\title{
Folate intake and atopic eczema in Japanese school children
}

\author{
A. Nishide ${ }^{1}$, H. Matsubara ${ }^{2}$, M. Nagai ${ }^{2}$, S. Kure ${ }^{2,3}$ and S. Kuriyama ${ }^{1}$ \\ ${ }^{1}$ International Research Institute of Disaster Science, Tohoku University, Sendai, Japan, ${ }^{2}$ Tohoku Medical Megabank \\ Organization, Tohoku University, Sendai, Japan and ${ }^{3}$ Department of Pediatrics, Graduate School of Medicine, Tohoku \\ University, Sendai, Japan
}

A previous cross-sectional study has shown a tendency towards a lower risk of atopic eczema with a higher folate intake, and the significant interaction effect between folate intake and MTHFR (C677 T) genotype, which reflects impaired folate metabolism in Danish adults ${ }^{(1)}$. However, the other study has reported both dietary folate intake and C677 T genotype were not associated with self-reported atopic eczema in children and their mother in the $\mathrm{UK}^{(2)}$. To gain insight into folate intake in the risk of atopic eczema, the aim of this study was to examine association between folate intake and atopic eczema.

We conducted a cross-sectional study involving seven elementary schools in Miyagi prefecture, Japan. Brief self-administered diet history questionnaire (BDHQ) $)^{(3)}$ and International Study of Asthma and Allergies in Childhood (ISAAC) ${ }^{(4)}$ were distributed to the parents of all school Japanese children in first grade to fifth grade aged $6 \mathrm{yr}$ to $11 \mathrm{yr}$ on $29^{\text {th }}$ August, $2017(\mathrm{n}=1397)$. Study participants were 403 children whose parents returned the questionnaires (response rate: $28.8 \%$ ). Of these, we analysed 401 children who were completely answered BDHQ and ISSAC. The exposure variable was the energy-adjusted folate intake assessed using BDHQ which was categorized at quartile points. The presence of atopic eczema was defined as "yes" for the following both question in ISAAC; "Has your child ever had an itchy rash which was coming and going for at least 6 months" and "Has your child had this itchy rash at any time in the last 12 months?". We used logistic regression analysis to estimate odds ratio (OR) and $95 \%$ confidence interval (CI) for prevalence of atopic eczema in quartile of folate intake adjusting for confounders. The lowest quartile category of folate intake was used as a reference category.

\begin{tabular}{|c|c|c|c|c|}
\hline & $\begin{array}{c}1^{\text {st }} \text { quartile } \\
(41 \mu \mathrm{g} / 1000 \mathrm{kcal}- \\
<110 \mu \mathrm{g} / 1000 \mathrm{kcal})\end{array}$ & $\begin{array}{c}2^{\text {nd }} \text { quartile } \\
(110 \mu \mathrm{g} / 1000 \mathrm{kcal}- \\
<140 \mu \mathrm{g} / 1000 \mathrm{kcal})\end{array}$ & $\begin{array}{c}3^{\text {rd }} \text { quartile } \\
(140 \mu \mathrm{g} / 1000 \mathrm{kcal}- \\
<172 \mu \mathrm{g} / 1000 \mathrm{kcal})\end{array}$ & $\begin{array}{c}4^{\text {th }} \text { quartile } \\
(\geq 172 \mu \mathrm{g} / \mathrm{kcal})\end{array}$ \\
\hline Number of participants & 100 & 101 & 100 & 100 \\
\hline Number of eczema & 38 & 26 & 31 & 27 \\
\hline Multivariate-adjusted OR(95\%CI)* & $1 \cdot 00($ ref $)$ & $0 \cdot 61(0 \cdot 33-1 \cdot 12)$ & $0 \cdot 76(0 \cdot 42-1 \cdot 38)$ & $0 \cdot 61(0 \cdot 33-1 \cdot 12)$ \\
\hline
\end{tabular}

Values are odds ratio (OR) and for prevalence of atopic eczema in quartile of folate intake. *Adjustment for age, sex, school (seven categories), Obesity Index: $\{$ (real weight - standard weight)/standard weight $\times 100\}^{(5)}$

Compared with folate intake in the first quartile, its intake in 2nd-4th quartiles had no significant association with a lower prevalence of atopic eczema. No significant linear trend existed $(\mathrm{P}$ for trend $=0.202)$, indicating that the quartiles with higher folate intake did not have less prevalence of atopic eczema. This study has several limitation that we did not actually observe the diet contents and the symptoms, because these data were obtained from self-administered questionnaires. However, these self-administered questionnaires have been used in previous several studies. Secondary, information on C677 T genotype was not available in this study. In conclusion, even though point estimates in 2nd-4th quartiles showed lower than 1st quartile, the results did not show any significant association between amount of folate intake and prevalence of atopic eczema. To determine the association between folate intake and allergic diseases, further studies with consideration of impaired folate metabolism by polymorphism of methylene-tetra-hydro folate reductase $\mathrm{C} 677 \mathrm{~T}$ are needed.

1. Husemoen LLN, Toft U, Fenger M et al. (2006) Int J Epidemiol 35, 954-961.

2. Granell R, Heron J, Lewis S et al. (2008) Clin Expe Allergy 38, 320-328.

3. Sasaki S, Yanagibori R, Amano K (1998) JEpidemiol 8, 203-215.

4. Haileamlak A, Lewis SA, Britton J et al. (2005) Brit J Dermatol 152, 735-741.

5. Ikiuo K, Hashimoto R, Murata Ml (2010) Child Health 69, 6-13. 